\title{
Retained common bile duct stones after endoscopic sphincterotomy: temporary and longterm treatment with biliary stenting
}

\author{
D G Maxton, D E F Tweedle, D F Martin
}

\begin{abstract}
Basket extraction after endoscopic sphincterotomy failed to clear the bile ducts immediately in $85(30 \%)$ of 283 consecutive patients with common bile duct stones. Temporary biliary drainage was established by the insertion of a single 7 Fr double pigtail stent before further planned endoscopic attempts at stone removal. In 84 patients (21 male: 63 female, mean age 77 years) this measure relieved biliary obstruction, mean serum bilirubin falling from 101 to $18 \mathrm{umol} / \mathrm{l}$ by the time of the second endoscopic retrograde cholangiopancreatography. Six patients died from non-biliary causes with temporary stents in situ. Common bile duct stone extraction was achieved endoscopically in 50 of the remaining 79 patients after a mean of $4 \cdot 3$ months (range $1-12), 34(68 \%)$ requiring only one further procedure. Three patients were referred for biliary surgery. Single stents were also effective for longterm biliary drainage in the remaining 26 elderly patients with unextractable stones. The main biliary complication of stenting was 13 episodes of cholangitis but all except one responded to medical treatment and early stent exchange. If common bile duct stones remain after endoscopic sphincterotomy, a single 7 Fr double pigtail stent is effective and safe for temporary biliary drainage before further endoscopic attempts at duct clearance and for longterm biliary drainage especially in the old and frail.

(Gut 1995; 36: 446-449)
\end{abstract}

Keywords: common bile duct stones, endoscopic sphincterotomy, biliary stenting.

Ideally, the common bile duct should be free of stones after the initial endoscopic procedure for choledocholithiasis. Leaving stones within the common bile duct exposes the patient to an increased risk of cholangitis, pancreatitis, and biliary obstruction. ${ }^{1-3}$ Complication rates are up to three times greater for patients with retained stones compared with those with successful duct clearance. ${ }^{3}$ Nevertheless, failed endoscopic common bile duct stone extraction is a common problem. Although it is claimed duct clearance can be accomplished endoscopically in $85-95 \%$ of cases, ${ }^{4}$ it is often not clear whether this represents success after single or repeated attempts or after using additional techniques, such as mechanical or extracorporeal shock wave lithotripsy (ESWL), which may not be generally available. Two recent studies from recognised centres have reported that initial attempts at common bile duct stone extraction were successful in only $73 \%$ and $80 \%$ of patients. ${ }^{56}$ In our own unit overall common bile duct clearance was $82 \%$ but this figure was achieved after a mean of 1.9 attempts. ${ }^{7}$ Success rates in less experienced units are likely to be substantially lower. There also remain around $5-10 \%$ of common bile duct stones that cannot be removed endoscopically even after repeated procedures using a variety of additional techniques. ${ }^{4}$

The treatment of retained common bile duct stones after endoscopic sphincterotomy is controversial. If urgent surgical exploration with its associated mortality is to be avoided especially in the elderly, temporary biliary drainage should be achieved. ${ }^{8} 9$ Biliary drainage is believed to reduce the incidence of complications and to permit elective surgical intervention or further endoscopic attempts at duct clearance. ${ }^{10}$ Nasobiliary intubation permits the use of dissolution therapy or ESWL but is uncomfortable for the patient. ${ }^{8}$ Failure of either of these treatments may require a further procedure to produce drainage. Insertion of an endoprosthesis (stent) achieves temporary drainage and reduces the risk of stone impaction. ${ }^{58}$ Biliary stents are also effective for longterm treatment of the small proportion of cases where the duct cannot be cleared after repeated attempts. ${ }^{81112}$ In this study we report the use of a single stent for temporary and longterm treatment of retained common bile duct stones. In contrast with other series, the emphasis was on using the technique to permit further endoscopic attempts at duct clearance rather than as a preliminary to elective surgery. 58

\section{Methods}

\section{PATIENTS}

Between March 1989 and June 1992, 283 patients were found to have definite common bile duct stones at endoscopic retrograde cholangiopancreatography (ERCP). Endoscopic sphincterotomy was performed in every patient and basket extraction of common bile duct stones attempted. In 85 patients complete clearance was not achieved immediately and a stent was inserted for temporary biliary drainage before further endoscopic attempts at duct clearance. This gives an overall incidence 
of retained stones of $30 \%$ and these patients formed the study group. There were 21 male and 64 female subjects with a mean age of 77.5 years (range 44-94). Cholecystectomy had been previously performed on $24(28 \%)$. The clinical presentation was jaundice in 39, cholangitis in 23 , and biliary colic or abnormal liver blood tests in the remainder. In general the patients were elderly and ill with either jaundice or cholangitis present in almost $75 \%$. Follow up data were obtained either at the time of admission for further ERCP or by telephone contact with the patients, their next of kin, general practitioners or referring consultants. Data were available on all subjects in the study group.

\section{TECHNIQUE}

ERCP was performed initially using an Olympus side viewing diagnostic JF200 duodenoscope with a 'small' $3.2 \mathrm{~mm}$ working channel as endoscopic sphincterotomy is more easily performed than with a larger channel instrument. Biliary drainage was achieved by inserting a single $7 \mathrm{Fr}$ double pigtail stent (Wilson-Cook, UK) with the proximal end above the stones and the distal end in the duodenum. The second and all subsequent ERCPs were carried out with the 'large' Olympus $4.2 \mathrm{~mm}$ channel therapeutic TJF200 duodenoscope. This permitted the 7 Fr stent to be removed through the working channel of the therapeutic instrument and the use of the more effective 'large' mechanical lithotripter (BML3Q: Olympus/Key-Med) to crush the remaining stones. If stones remained in the bile duct at the end of each procedure, the stent was replaced and ERCP repeated. The interval between ERCPs was between two and three months. If it was decided that the stones were too large for successful endoscopic extraction or the patient too frail and elderly for further frequent attempts, the single stent was left for longterm biliary drainage. Stent exchanges were then scheduled every 6-12 months to review progress and attempt stone extraction.

\section{ADDITIONAL PROCEDURES}

Mechanical lithotripsy was used to assist common bile duct clearance in 23 patients. In the early part of the study ESWL was used in a further 11 patients and dissolution therapy through a nasobiliary catheter in $10 .{ }^{13}$

\section{Results}

\section{TEMPORARY STENTS}

In 84 of 85 patients the acute biliary problem resolved or improved with endoscopic sphincterotomy and temporary stenting, serum bilirubin falling from $101(135) \mu \mathrm{mol} / 1$ (mean (SD)) to 18 (22) $\mu \mathrm{mol} / \mathrm{l}$ between initial and second ERCP. The serum alkaline phosphatase halved from 636 (366) IU/l (mean (SD)) to 310 (288) over the same period.

A 91 year old patient died of a respiratory

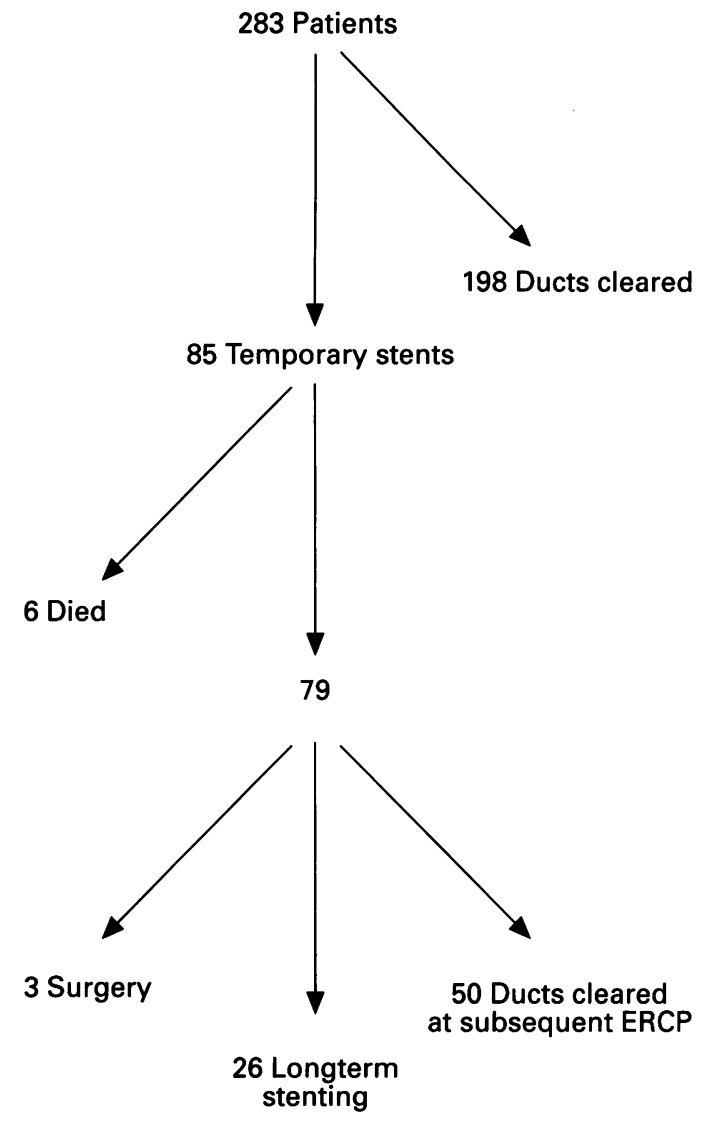

Figure 1: Outcome of patients presenting with choledocholithiasis.

arrest on the day of initial ERCP. Five other patients died with temporary stents in situ, all from causes unrelated to biliary disease. Two died from cardiovascular disease, two from disseminated malignancy, and one from respiratory insufficiency. Figure 1 shows the clinical outcome in the remaining 79 patients. Three patients were referred for surgical common bile duct clearance. One patient with a temporary stent in situ developed cholangitis and had elective surgery at another hospital. The remaining two patients were fit, aged under 60 , and had large stones remaining in the common bile duct after three and six attempts respectively at endoscopic extraction.

\section{SUCCESSFUL CLEARANCE}

In $50(63 \%)$ of 79 patients, the common bile duct was eventually cleared of stones and the temporary stent removed. In over two thirds $(68 \%)$ of these only one further ERCP was required to clear the bile duct but up to four were performed in some patients (Fig 2). A mean of 4.3 months (range 1-12) elapsed before treatment was completed. Seven episodes of cholangitis occurred in the 50 subjects and were successfully treated medically in all with intravenous antibiotics, fluids and early, but not emergency, stent replacement.

\section{LONGTERM STENTS}

In 26 subjects, representing $9 \cdot 2 \%$ of the 283 with common bile duct stones, duct clearance 


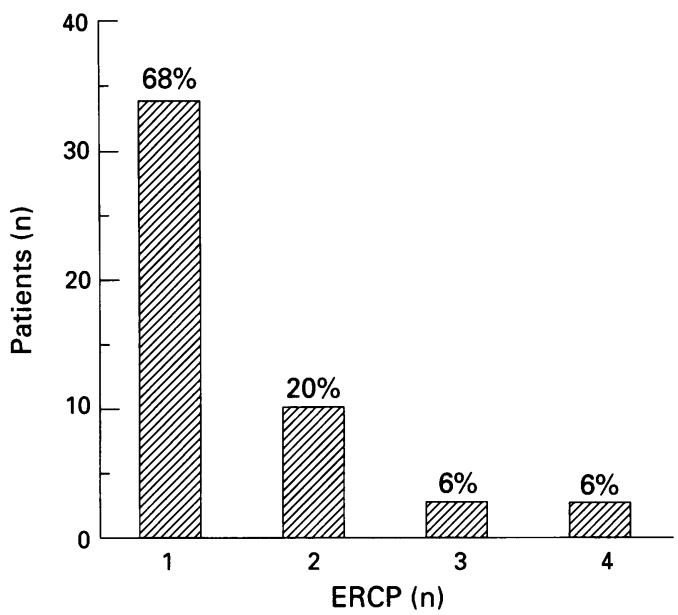

Figure 2: Number of additional ERCPs required to achieve common bile duct clearance after temporary stenting.

was unsuccessful and single stents left to provide longterm biliary drainage. Twenty one patients still had their gall bladder remaining. These longterm stents have all been in situ for over 12 months. Patients were elderly with a mean age of 82 years (range 65-94) and frequently had other general medical problems. Four died from non-biliary causes during a mean follow up period of 24 months (range 12 to 46). The only significant biliary complication seen was four episodes of cholangitis successfully treated as already outlined without surgical intervention.

\section{Discussion}

This study confirms that single $7 \mathrm{Fr}$ stents provide effective temporary biliary drainage when common bile duct clearance fails after endoscopic sphincterotomy and that urgent surgical intervention can be avoided. ${ }^{58}$ Temporary biliary stenting also permits transfer of sick patients to more expert centres with a reduced risk of biliary sepsis. In a previous series, however, surgery was still performed in $20-25 \%$ of patients with retained common bile duct stones after temporary stenting. ${ }^{5}$ We could clear the bile ducts endoscopically in over two thirds of such patients, most needing only one further ERCP. Nine per cent of the original group of patients with choledocholithiasis remained with common bile duct stones and longterm stents. All were both elderly and frail. In other studies where a more active surgical policy was pursued there also remained a small number of patients in whom both endoscopic clearance failed and surgery was contraindicated. ${ }^{68}$ Our final figure for longterm stenting is similar to these and in the absence of biliary related mortality suggests surgical intervention was not unnecessarily delayed or withheld in our patients.

The $30 \%$ incidence of retained common bile duct stones after initial ERCP is a little greater than others ${ }^{5} 614$ but additional factors contributing to a comparatively high figure may be patient selection and referral patterns in a specialist centre and an unwillingness to assume that even small stones would pass spontaneously. Both large (10 Fr) and small ( 5 or $6.5 \mathrm{Fr}$ ) straight and pigtail stents used alone or in pairs have been reported to be effective for biliary drainage. 58111215 The choice of a single $7 \mathrm{Fr}$ double pigtail stent was purely practical. One stent is quick and easy to insert. In addition, $7 \mathrm{Fr}$ stents can be placed using the smaller 2.8 or $3.2 \mathrm{~mm}$ channel instruments and easily extracted, even 'doubled over', through the therapeutic $4 \cdot 2 \mathrm{~mm}$ channel of the larger duodenoscope. It does not seem that stent selection is critical to the success of the technique.

Longterm stenting is also valuable for the elderly with other medical problems that might make surgical exploration hazardous. ${ }^{11} 1516$ Again several types of stent have been shown to be effective over the long term and single $7 \mathrm{Fr}$ stents can now be included. ${ }^{811} 12$ It does seem that endoscopic sphincterotomy should be performed in all patients requiring stenting for common bile duct stones as complications and particularly biliary related deaths are more frequent in those without an endoscopic sphincterotomy, ${ }^{5}$ but no direct comparison has been made between endoscopic sphincterotomy with stenting and endoscopic sphincterotomy alone. It may be that endoscopic sphincterotomy is more important than stenting in improving biliary drainage. In common with others, we have found mechanical lithotripsy to be the most effective complementary technique. ${ }^{1718}$ The addition of oral ursodeoxycholic acid treatment to longterm stenting has recently been reported to facilitate later common bile duct stone removal and reduce the incidence of cholangitis. ${ }^{19}$

As might be expected, with both stones and a stent remaining in the common bile duct, there is a significant incidence of cholangitis in studies of temporary and longterm stenting 5811 and this was the only significant biliary complication in this series. There was no mortality related, however, to cholangitis treated by intravenous fluids antibiotics and stent exchange on the next available routine ERCP list. Complications were not confined to those with a gall bladder in situ as has been suggested. ${ }^{5}$

Insertion of a single $7 \mathrm{Fr}$ biliary stent is an effective method of establishing temporary biliary drainage in patients with retained common bile duct stones after endoscopic sphincterotomy. Further endoscopic attempts at bile duct clearance are successful in most cases and small stones may pass spontaneously. If endoscopic stone extraction is not achieved a single biliary stent is a safe alternative to surgery particularly in the frail and elderly. Longterm biliary stenting seems to give satisfactory symptom relief in such patients but the technique requires prolonged evaluation and follow up. The main risk is cholangitis but this complication can be treated without resorting to operative intervention. Surgical exploration can then be limited to the younger, fitter subjects with unextractable stones after, perhaps, two or three unsuccessful endoscopic attempts. 
1 Davidson BR, Neoptolemos JP, Carr-Locke DL. Endoscopic sphincterotomy for common bile duct calculi in patients with gallbladder in-situ considered unfit for surgery. Gut 1988; 29: 114-20.

2 Martin DF, McGregor JC, Lambert ME, Tweedle DEF. Stone extraction after endoscopic sphincterotomy - an active policy is best. Gut 1986; 27: A1360-1.

3 Neoptolemos JP, Davidson BR, Shaw DE, Lloyd D, CarrLocke DL, Fossard DP. Study of common bile duct exploration and endoscopic sphincterotomy in a consecutive series of 438 patients. Br $\mathcal{F}$ Surg 1987; 74: 916-21.

4 Cotton PB. Endoscopic management of bile duct stones; (apples and oranges). Gut 1984; 25: 587-97.

5 Peters R, MacMathuna P, Lombard M, Karani J, Westaby D. Management of common bile duct stones with a biliary endoprosthesis. Report of 40 cases. Gut 1992; 33: 1412-5.

6 Vaira D, D'Anna L, Ainley C, et al. Endoscopic sphincterotomy in 1000 consecutive patients. Lancet 1989; ii: 431-4.

7 Lambert ME, Betts CD, Hill J, Faragher EB, Martin D F, Tweedle DEF. Endoscopic sphincterotomy: the whole Tweedle DEF. Endoscopic sphin

8 Cairns SR, Dias L, Cotton PB, Salmon PR, Russell RCG. Additional endoscopic procedures instead of urgent surgery for retained common bile duct stones. Gut 1989; 30: $535-40$

9 Kiil J, Kruse A, Rokkjaer M. Endoscopic biliary drainage. Br $\mathcal{F}$ Surg 1987; 74: 1087-90.

10 Lygidakis NJ, Brummelkamp WH. Bacteraemia in relation to intrabiliary pressure in proximal v distal malignant biliary obstruction. Acta Chir Scand 1986; 152: 305-7.
11 Cotton PB, Forbes A, Leung JWC, Dineen L. Endoscopic stenting for long-term treatment of large bile duct stones: 2- to 5-year follow-up. Gastrointest Endosc 1987; 33: $411-2$

12 Siegel JH, Yatto RP. Biliary endoprostheses for the management of retained common bile duct stones. $A m$ F

13 Nicholson DA, Martin DF. Tweedle DEF, Rao PN. Management of common bile duct stones using a secondManagement of common bile duct stones using a secondgeneration extracorporea

14 Leese T, Neoptolemos JP, Baker AR, Carr-Locke DL. Management of acute cholangitis and the impact of endoscopic sphincterotomy. Brf Surg 1986; 73: 988-92.

15 Kiil J, Kruse A, Rokkjaer M. Large bile duct stones treated by endoscopic biliary drainage. Surgery 1989; 105: 51-6.

16 Van Steenbergen W, Pelemans W, Fevery J. Endoscopic biliary endoprosthesis in elderly patients with large bile duct stones: Long-term follow-up. $\mathcal{F}$ Am Geriatr Soc 1992; 40: 57-60.

17 Winslet MC, Neoptolemos JP. The place of endoscopy in the management of gallstones. In: Carr-Locke DL. Endoscopy update. Ballieres Clin Gastroenterol 1991; 5: 1 .

18 Chung SCS, Leung JWC, Leong HT, Li AKC. Mechanical lithotripsy of large common bile duct stones using a basket. Br f Surg 1991; 78: 1448-50

19 Johnson GK, Geenan JE, Venu RP, Schmalz MJ, Hogan WJ. Treatment of non-extractable common bile duct stones with combination ursodeoxycholic acid plus endoprosthesis. Gastrointest Endosc 1993; 39: 528-31. 